\title{
Commentary: Carinal pneumonectomy: Not for the faint of heart
}

\author{
Benny Weksler, MBA, MD
}

\footnotetext{
From the Division of Thoracic Surgery, Department of Thoracic and Cardiovascular Surgery, Allegheny General Hospital, Pittsburgh, Pa.

Disclosures: Proctor for Intuitive Surgery Speaker for AstraZeneca.

Received for publication Dec 5, 2018; accepted for publication Dec 6, 2018; available ahead of print Jan 11, 2019. Address for reprints: Benny Weksler, MBA, MD, Division of Thoracic Surgery, Department of Thoracic and Cardiovascular Surgery, 320 E. North Ave 14th Fl, South Tower, Pittsburgh, PA 15212 (E-mail: benny.weksler@ ahn.org).

J Thorac Cardiovasc Surg 2019;157:2084-5

$0022-5223 / \$ 36.00$

Copyright $(2) 2018$ by The American Association for Thoracic Surgery

https://doi.org/10.1016/j.jtcvs.2018.12.021
}

Thoracic surgeons face few operations that are more complex than carinal resection and in particular carinal pneumonectomy. In less-experienced hands, procedural mortality greater than $25 \%$ is not uncommon. ${ }^{1}$ Training and proficiency in the procedure are hard to achieve because of the rarity of central airway lesions. Earlier detection of lung cancer and advanced imaging may further reduce need for carinal resection. Even experienced centers seldom see more than 2 patients a year who require a carinal resection.

Arguably, the pioneer in performing complex airway surgery and training residents in the procedure was Dr Hermes Grillo. His landmark book, Surgery of the Trachea and Bronchi, is a mandatory read for any thoracic surgeon with interest in airway surgery. ${ }^{2}$ In 1999, Grillo and colleagues from the Massachusetts General Hospital (MGH) published their experience spanning almost 4 decades of carinal surgery with a very respectable mortality of $12.7 \%$ including patients who underwent carinal pneumonectomy. ${ }^{3}$

In this issue of the Journal, Costantino and colleagues ${ }^{4}$ updated the MGH experience with carinal resection, reporting on 45 patients operated on during a 20 -year period, from 1997 to 2017, a more modern era of surgery and anesthesia. Combined carinal and lung resection was performed in 24 patients $(53 \%)$; the majority were carinal pneumonectomies (23 patients, $51 \%$ ). Most commonly, these surgeries were approached by right thoracotomy or median sternotomy. Circulatory support was used in 4 patients; cardiopulmonary bypass was electively used in 3 , and venoarterial extracorporeal membrane oxygenation was used in 1 . There were 5 anastomotic complications, but only 1 patient required surgical therapy, an improvement over Grillo and colleague's 1962 to 1996 MGH series. Three patients $(6.7 \%)$ died within 30 days of carinal resection; all had undergone carinal pneumonectomy. The mortality in patients who underwent carinal pneumonectomy was $13 \%(3 / 23)$, and there was no mortality $(0 \%)$ in patients who underwent

\section{References} BC Decker; 2004.

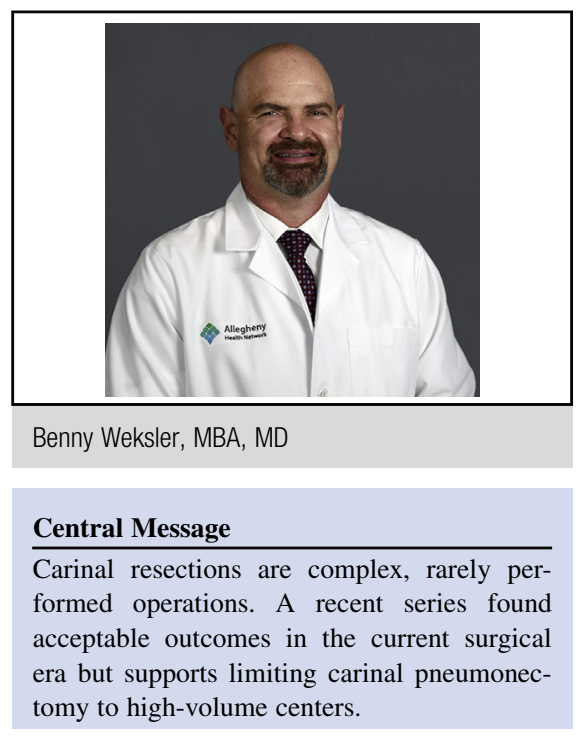

See Article page 2073.

carinal resection without pneumonectomy. Even at the Massachusetts General Hospital, a high-volume center, carinal resection was performed only twice a year on average.

The series of Costantino and colleagues is an important report that stresses the difficulty of carinal surgery, in particular, the difficulty of carinal pneumonectomy. The 4 lessons learned and detailed by the authors will serve all surgeons well: (1) Patients should be carefully selected for carinal resection, taking medical fitness, lymph node status, and technical planning into account; (2) the surgeon should aim for an R0 resection but not at the expense of anastomotic tension; (3) circulatory support should be used when warranted; and (4) patients who are likely candidates for carinal resection should be referred to a high-volume center. Even in the experienced hands at MGH, carinal pneumonectomy carried a mortality of $13 \%$. Although minimally invasive techniques may assist in reducing the morbidity and mortality of carinal resection and could allow more surgeons to perform carinal resections safely, carinal pneumonectomy should be performed at a high-volume center because of the rarity of these cases.

1. Jensik RJ, Faber LP, Kittle CF, Miley RW, Thatcher WC, El-Baz N. Survival in patients undergoing tracheal sleeve pneumonectomy for bronchogenic carcinoma. J Thorac Cardiovasc Surg. 1982;84:489-96.

2. Grillo HC. Surgery of the Trachea and Bronchi. Hamilton, Ontario, Lewiston, NY: 
3. Mitchell JD, Mathisen DJ, Wright CD, Wain JC, Donahue DM, Moncure AC, et al. Clinical experience with carinal resection. J Thorac Cardiovasc Surg. 1999;117: $39-53$.
4. Costantino CL, Geller AD, Wright CD, Ott HC, Muniappan A, Mathisen DJ, et al. Carinal surgery: a single-institution experience spanning 2 decades. J Thorac Cardiovasc Surg. 2019;157:2073-83.e1. 